\title{
Temperature Effects on Sulphur Catalyzed Dimerization of Fluted Pumpkin (Telfairia Occidentalis)
}

\author{
B.A. Ikyenge ${ }^{1}$, J.T. Ageh ${ }^{2}$, L. Akaazwana ${ }^{3}$ and L. Leke ${ }^{1}$ \\ ${ }^{I}$ Department of Chemistry Benue State University, P.M.B. 102119 Makurdi, Nigeria. \\ ${ }^{2}$ Department of Integrated Science, College of Education Katsina-Ala Benue State \\ ${ }^{3}$ Department of Chemistry, College of Agriculture Yandev, Benue State.
}

\begin{abstract}
Pumpkin seed oil (4268.5g) was solvent extracted from seeds of the fluted pumpkin (Telfairia occidentalis), using petroleum ether $\left(60^{\circ}-80^{\circ} \mathrm{C}\right)$. Samples of the oil were dimerized at varying temperatures ranging from $300^{\circ}-350^{\circ} \mathrm{C}$; using $5 \%$ (based on the weight of oil) sulphur catalyst and a maximum reaction time of 45 minutes under nitrogen atmosphere. Extent of reaction was determined by measuring changes in molecular weight and acid values of the dimerized oil samples which were found to increase with temperature and time of dimerization. A dimer yield of $42.53 \%$ was obtained in the process whose progress is a function of temperature and reaction time. This yield is high compared with $18.7 \%$ obtained when Iodine catalyst was used. Preparative TLC gave an optimum dimer yield of $42.53 \%$ at a temperature of $340^{\circ} \mathrm{C}$ and a reaction time of 35 minutes.
\end{abstract}

Keywords: Telfairia occidentalis, dimerized oil, dimer acid.

\section{Introduction}

The quest for industrial raw materials based on natural renewable resources which can serve as an alternative to petroleum, has been of interest to many researchers in recent times. Vegetable oils such as soybean oil, tall oil, and safflower oil, among others, are increasingly being used as such alternatives. They have provided numerous intermediates like dimer fatty acids which find application in the manufacture of coatings, adhesives, printing inks, cosmetics, etc. Dimer acids are dibasic acids derived from thermal or catalytic polymerization reactions of the simple monohydric esters of drying or semi-drying oils. They are predominantly C36 dicarboxylic acids with small fraction of monocarboxylic acids and some C54 tricarboxylic acids [1,2]. Dimerization of vegetable oleic acid or tall oil fatty acid (TOFA) yields dimer acids, originally introduced in the 1950s by General Mills Chemicals and Emery (now Cognis Corp.). It is a complex reaction that generally gives a mixture of aliphatic branched and cyclic C36 - diacids (dimer acid) as the main product, apart from trimer acids and higher condensed polymer acids as well as other products such as isostearic acid, un-reacted oleic and stearic acids [3].

In a study by infrared (IR) spectophotometry of the isomerization of linseed oil during its polymerization, it was established that the formation of trans-isomers enhanced the polymerization reaction [4]. Subsequently, Cecehi et al showed that dimer structures and hence the mechanism of its production could be a function of the method of its formation. They obtained methyl linoleate dimer through thermal and thermocatalytic polymerization using ruthenium catalyst and confirmed two structures, cyclic (mono- and bi-), and aliphatic structures, respectively, for the two different production routes [5]. High molecular weight soybean oil polymers were isolated by Tao et al, by distillation and mass spectrometric analysis and observed that they were dimers formed by Diels-Alder reaction [6]. Kikawa showed that a low temperature process $\left(50^{\circ}-200^{\circ} \mathrm{C}\right)$ involving the use of activated clay and oxygen/nitrogen mixture was used to dimerized and purified crude unsaturated fatty acids [7]. Tao reported that the optimum condition for the polymerization of soybean oil is $350^{\circ} \mathrm{C}, 0.0025 \%$ iodine catalyst and a reaction time of 20minutes under inert atmosphere [8].

The fatty acid precursors used for the dimerization and oligomerization are generally tall oil, soybean oil, and rapeseed oil or dehydrated castor oil. The diversification of the sources of precursors for the production of dimer acids will reduce pressure on the aforementioned oils which are already in use in many domestic and industrial applications. It is in the light of the above that a locally available alternative in Nigeria, namely, pumpkin seed oil fatty acid, obtainable from Telfairia occidentalis seed oil is used. Furthermore the choice of pumpkin seed oil as a fatty acid feedstock is based on the fact that it contains fatty acids of oleic and linoleic (about 63\% of the fatty acids), and a high degree of unsaturation, hence its drying properties [9].

This work is a report on the dimerizability of pumpkin seed oil, PSO, using sulphur catalyst [10] to establish the optimum reaction conditions and obtain some thermodynamic data on the dimerization process. 


\section{Experimental}

Pumpkin seed oil, PSO, was solvent extracted from seeds (obtained at the Ibagwa market, near Nsukka, Enugu State), using low boiling petroleum ether $\left(60^{\circ}-80^{\circ} \mathrm{C}\right)$. The oil extracted was water degummed and alkali refined.

Modified method of Tao [10] was used for dimerization of pumpkin seed oil.

Dimer yield was determined by preparative thin layer chromatography using a mixture of solvents consisting of $n$-hexane, diethyl ether and glacial acetic acid in the ratio 7: 2.9: 1. Both the extracted and the dimerized PSO samples were characterized using A.O.A.C. methods [11]. The following physicochemical properties: acid value, saponification value, specific gravity, refractive index and iodine value were also determined using the methods described by A.O.A.C.[11]. The molecular weight and acid values of dimer acid samples were determined by cryoscopic method and colour by (Gardner).

\section{Results And Discussion}

The physicochemical properties of Telffairia Occidentalis are shown in Table 1.0. The oil yield of $46 \%$ indicates its potential in the manufacture of oleochemicals and falls within the value as reported in literature [9]. The iodine value of 115.3 indicated that the oil is semi-drying oil consisting predominantly of poly unsaturated fatty acids, with a potential in surface coating.

Table 1.0 Physicochemical Properties of Telffairia Occidentalis

\begin{tabular}{|lc|}
\hline Property & Value \\
\hline Oil yield & $46 \% \pm 0.71$ \\
Refractive index & $1.466 \pm 0.002$ \\
Acid value $(\mathrm{mg} / \mathrm{KOH})$ & $3.68 \pm 0.21$ \\
Saponification $(\mathrm{mg} / \mathrm{KOH})$ & $198.6 \pm 0.21$ \\
Iodine value & $115.3 \pm 0.05$ \\
Colour $($ Gardner $)$ & $5 \pm 0.00$ \\
\hline
\end{tabular}

The molecular weights obtained from cryoscopic determination of dimer acid samples drawn at an interval of 5 minutes are shown in Table 2.0. The molecular weight was found to increase with time and temperature of reaction. This was due to increase rate of polymerization with temperature and time [12].

Table 2.0 Molecular Weight of the Dimer Acids Samples

\begin{tabular}{|c|c|c|c|c|c|c|}
\hline $\begin{array}{l}\text { Tim } \\
\text { (Mi }\end{array}$ & $300^{\circ} \mathrm{C}$ & $310^{\circ} \mathrm{C}$ & $320^{\circ} \mathrm{C}$ & $330^{\circ} \mathrm{C}$ & $340^{\circ} \mathrm{C}$ & $350^{\circ} \mathrm{C}$ \\
\hline 0 & $937.80 \pm 0.06$ & $965.78 \pm 1.36$ & $969.62 \pm 0.76$ & $972.52 \pm 0.87$ & $987.52 \pm 0.97$ & $1029.62 \pm 1.62$ \\
\hline 5 & $1333.30 \pm 0.35$ & $1492.53 \pm 0.67$ & $1503.75 \pm 0.89$ & $1503.75 \pm 0.76$ & $1508.29 \pm 0.70$ & $1536.42 \pm 0.56$ \\
\hline 10 & $1515.15 \pm 0.53$ & $1538.46 \pm 0.51$ & $1563.72 \pm 0.87$ & $1563.72 \pm 1.76$ & $61591.09 \pm 1.41$ & $1601.28 \pm 0.96$ \\
\hline 15 & $1574.80 \pm 0.37$ & $1587.30 \pm 0.93$ & $1632.65 \pm 0.67$ & $1632.65 \pm 0.85$ & $1644.74 \pm 0.93$ & $1647.45 \pm 0.43$ \\
\hline 20 & $1639.34 \pm 0.24$ & $1652.89 \pm 0.56$ & $1687.76 \pm 0.89$ & $1687.76 \pm 2.00$ & $1686.34 \pm 1.60$ & $1690.62 \pm 1.10$ \\
\hline 25 & $1666.67 \pm 0.67$ & $1680.67 \pm 1.51$ & $1760.56 \pm 1.12$ & $1760.56 \pm 0.51$ & $1776.20 \pm 0.82$ & $1780.94 \pm 0.56$ \\
\hline 30 & $1716.74 \pm 1.47$ & $1739.67 \pm 0.98$ & $1765.22 \pm 0.80$ & $1765.56 \pm 1.90$ & $1785.71 \pm 0.96$ & $1780.42 \pm 0.72$ \\
\hline 35 & $1785.71 \pm 0.57$ & $1739.72 \pm 0.37$ & $1831.50 \pm 0.24$ & $1830.82 \pm 1.10$ & $1845.02 \pm 0.76$ & $1848.43 \pm 0.91$ \\
\hline 40 & $1801.80 \pm 0.37$ & $1818.18 \pm 0.47$ & $1848.43 \pm 0.37$ & $1848.76 \pm 0.8$ & $1865.67 \pm 1.02$ & $1870.91 \pm 0.82$ \\
\hline 45 & $1834.86 \pm 0.36$ & $1836.54 \pm 0.62$ & $1856.57 \pm 1.07$ & $1858.64 \pm 0.67$ & $1879.70 \pm 1.74$ & $1893.94 \pm 1.32$ \\
\hline
\end{tabular}

Plot of molecular weight as a function of time at various temperatures of the reaction

Fig. 1 illustrates this increasing trend. 


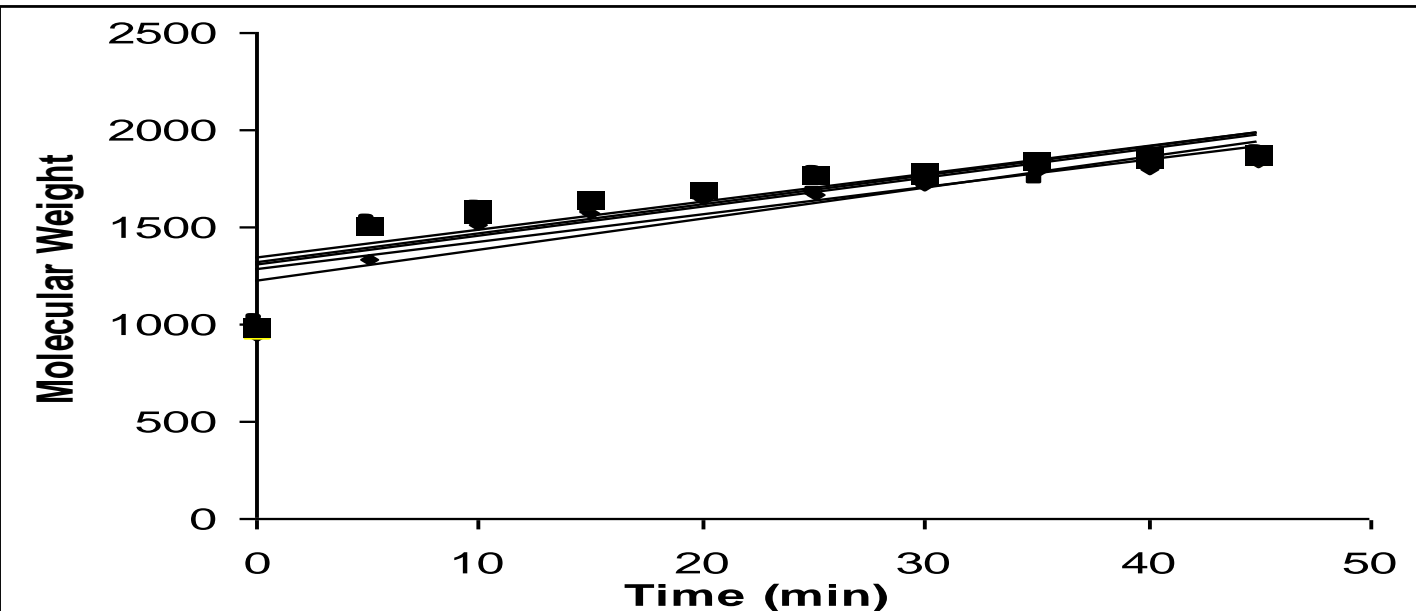

Fig.1 Plot of Molecular Weight versus Time

Table 3.0 shows the results of the acid values of dimer acid samples drawn at an interval of five minutes and temperature range between $300-350^{\circ} \mathrm{C}$

Table 3.0: Acid Values of Dimer Acid Samples

\begin{tabular}{|ccccccc|}
\hline $\begin{array}{c}\text { Time } \\
\text { (Min) }\end{array}$ & $\mathbf{3 0 0}^{\mathbf{}} \mathbf{C}$ & $\mathbf{3 1 0}^{\mathbf{C}} \mathbf{C}$ & $\mathbf{3 2 0}^{\mathbf{}} \mathbf{C}$ & $\mathbf{3 3 0}^{\mathbf{}} \mathbf{C}$ & $\mathbf{3 4 0}^{\mathbf{}} \mathbf{C}$ & $\mathbf{3 5 0}^{\mathbf{}} \mathbf{C}$ \\
\hline 0 & $3.96 \pm 0.43$ & $5.76 \pm 1.94$ & $6.26 \pm 0.45$ & $8.67 \pm 0.04$ & $9.18 \pm 0.87$ & $12.22 \pm 0.25$ \\
5 & $4.82 \pm 0.89$ & $6.31 \pm 0.89$ & $7.35 \pm 2.03$ & $9.67 \pm 0.40$ & $11.67 \pm 0.49$ & $14.67 \pm 0.45$ \\
10 & $5.75 \pm 0.08$ & $7.82 \pm 0.04$ & $8.23 \pm 0.75$ & $10.52 \pm 0.47$ & $13.61 \pm 1.63$ & $16.28 \pm 0.64$ \\
15 & $7.67 \pm 0.17$ & $8.52 \pm 0.48$ & $9.42 \pm 1.46$ & $11.63 \pm 0.31$ & $15.73 \pm 0.45$ & $19.62 \pm 0.03$ \\
20 & $8.62 \pm 1.32$ & $9.07 \pm 2.32$ & $11.25 \pm 0.97$ & $13.61 \pm 0.27$ & $17.56 \pm 0.16$ & $21.55 \pm 0.02$ \\
25 & $9.32 \pm 0.75$ & $10.50 \pm 0.75$ & $12.62 \pm 1.87$ & $15.16 \pm 0.73$ & $19.32 \pm 0.08$ & $25.62 \pm 0.04$ \\
30 & $10.56 \pm 0.09$ & $11.63 \pm 1.01$ & $13.55 \pm 0.89$ & $17.23 \pm 0.42$ & $20.64 \pm 0.47$ & $28.15 \pm 0.06$ \\
35 & $12.44 \pm 2.02$ & $13.64 \pm 1.75$ & $14.96 \pm 1.09$ & $19.32 \pm 0.56$ & $23.62 \pm 0.65$ & $31.63 \pm 0.05$ \\
40 & $14.63 \pm 1.62$ & $15.49 \pm 1.17$ & $16.56 \pm 0.49$ & $21.44 \pm 0.64$ & $26.88 \pm 0.41$ & $35.60 \pm 0.23$ \\
45 & $16.78 \pm 0.00$ & $17.26 \pm 2.63$ & $19.62 \pm 0.48$ & $23.52 \pm 0.05$ & $28.13 \pm 0.76$ & $39.60 \pm 0.06$ \\
\hline
\end{tabular}

From Table 3.0, the acid values increases steadily with time and temperature of reaction. This implies that more acid groups were formed with increase in temperature and time elapse. This increase could be attributed to the production of free fatty acids during isomerization of bonds [13]. Plot of acid values as a function of time, Fig 2, illustrates this trend.

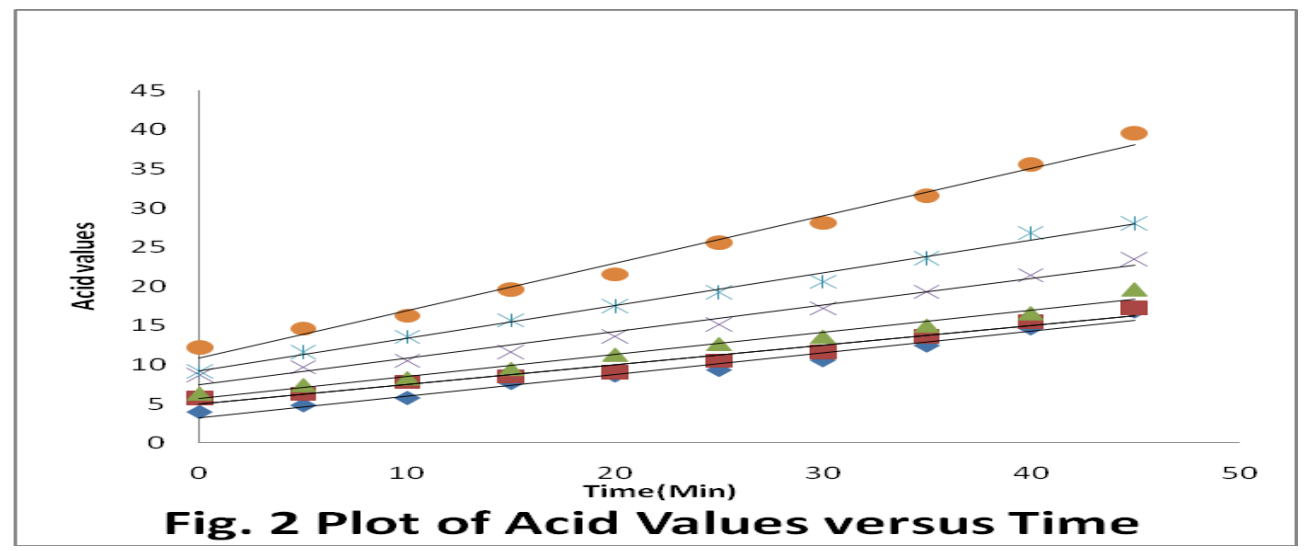

The results of the preparative TLC are given in (Table 1.2). The samples were selected at different temperatures at the dimerization time interval of 35 minutes to establish the optimum temperature of dimerization. The percentage yield increases with temperature up to $340^{\circ} \mathrm{C}$. However there was a decrease in the percentage dimer from $350^{\circ} \mathrm{C}$. This could be due to the formation of higher polymerization product of dimerization notably trimer. 
Table 3.0. Percentage Dimer Yield from TLC Analysis.

\begin{tabular}{|lcc|}
\hline Temp. at 35min. & No. of components & \% \\
\hline $300^{\circ} \mathrm{C}$ & 2 & $13.6 \pm 0.05$ \\
$310^{\circ} \mathrm{C}$ & 2 & $13.8 \pm 0.02$ \\
$320^{\circ} \mathrm{C}$ & 2 & $18.7 \pm 0.06$ \\
$330^{\circ} \mathrm{C}$ & 3 & $25.8 \pm 0.02$ \\
$340^{\circ} \mathrm{C}$ & 3 & $42.53 \pm 0.05$ \\
$350^{\circ} \mathrm{C}$ & 3 & $40.62 \pm 0.07$ \\
\hline
\end{tabular}

\section{Conclusion}

The results of the study revealed that temperature and time of dimerization have effect on the rate of dimerization as well as the dimer yield of the products. It also established that the optimum temperature of dimerization of pumpkin seed oil using sulphur catalyst is $340^{\circ} \mathrm{C}$ at 35 minutes.

\section{References}

[1]. Breuer, T. E., Dimer Acids. In: Kirk Othmer, ed. Encyclopedia of Chemical Technology, $4^{\text {th }}$ edition, New York: John Wiley \& Sons, 1979, 7, 768-782.

[2]. Parker, D.H., Principles of Surface Coating Technology. Interscience Publishers 1965, p.120.

[3]. Hill, K. Fats and Oils as Oleochemical Raw Materials, Pure and Appl. Chem., 2000; 72(7), 1255-1264.

[4]. Helme, J.P. and Molines, J., Study by IR Spectrophotometry of the Isomerization of Linseed Oil during its Thermal Polymerization: Application to Alkyd Resin Modified Oils, Rev. Franc. Corps Gras, 1957, 189-202.

[5]. Cecehi, G., Biasini, S., Ucciani, E. and Perrin, J. L., Thermal and Catalytic Dimerization of Linoleic Chain, Rev. Franc. Corps Gras., 1986, 33(12) 483-487

[6]. Tao, B.Y., Wang, P.-L. and Okos, M. (2001). Synthesis of Biopolymer and Polyesters from Soybean Oil and Carbohydrates, available at http://www.ecnext.com as at $26^{\text {th }}$ July, 2006.

[7]. Kikawa, H., Yamagishi, H. and Takagi, M., Preparation of Higher Unsaturated Fatty Acid (Ester) Dimers with Redduced Fluorescence, Japan Kokkai Tokyo, 1997, 97, 293-301.

[8]. Tao, B.Y. (2001). Determination of the Sum of Dimer and Polymer Triglyceides and of Acid Value of Used Frying Fats and Oils by Near IR Reflectance Spectroscopy (Boot-AJ), Available at http://www.ecnext.com as at $26^{\text {th }}$ July, 2006.

[9]. Asiegbu, J.E., Some Biological Evaluation of Fluted Pumpkin Seed. J. Sci. Food Agric., 1987, 40: 151-155

[10]. Tao, B.Y. (2001). Determination of the Sum of Dimer and Polymer Triglycerides and of Acid Value of Used Frying Fats and Oils by Near IR Reflectance Spectroscopy (Boot-AJ). Available at www.ecnext.com, as at $26^{\text {th }}$ July, 2006.

[11]. A. O. A. C. (2008) Official Methods of Analysis of the Association of Official Analytical Chemist (AOAC) $18^{\text {th }}$ Edition, Association of Official Analytical Chemist Washington D. C.

[12]. Johnson R. W. (1982) Dimerisation and Polymerization Pyde E. H. (ED). Fatty acids Am oil Chem. Soc. Campaign.

[13]. Ejikeme, P. M. and Ibemesi, J. A., New Alkyd Resin Systems from Blends of Melon Seed and Linseed Oils: The Case of Pentaerithritol as Polyhydric Alcohol, J. Chem. Soc. Nigeria, 2007, 32(2), 184-190. 